\title{
DeCOMPOSITION FACTORS HOUSEHOLd ENERGY SUBSIDY CONSUMPTION IN INDONESIA: KAYA IDENTITY AND LMDI APPROACH
}

\author{
Eka Sudarmaji*
}

Department Doctoral Student

IPB University \& University of Pancasila, Jakarta

Indonesia

esudarmaji@univpancasila.ac.id

Noer Azam Achsani

Department School of Business

IPB University, Bogor

Indonesia

achsani@yahoo.com

Yandra Arkeman

Department Program Studi Teknologi Industri Pertanian

IPB University, Bogor

Indonesia

yandra.arkeman@gmail.com

\section{Idqan Fahmi}

Department School of Business

IPB University, Bogor

Indonesia

ifahmi@mb.ipb.ac.id

*Corresponding Author email: esudarmaji@univpancasila.ac.id 


\section{A B S T R A C T}

For decades, the subsidy had prompted excessive and wasteful while offering little motivation to boost energy efficiency or reduce domestic greenhouse gas emissions. This paper aimed to measure household subsidy energy by examining the relationship between the other ten variables. The Logarithmic Mean Divisia Index (LMDI) and decomposition index were deployed to recognize the determinant effects that drive household's subsidy energy consumption. This study also presented an ARDL model applied. The robustness of the Granger Causality, Long-run, and Short-run causality during 1990-2017 was assessed. Based on LMDI, we found out that Population, Income Per Capita, Ratio National Renewal Energy over Fuel Fossil, Gross Capital Stock, Urban Household Consumption, and Ratio Household Subsidy were the positive factors that aggravate the change in household energy subsidy. The negative sign of Ratio National Energy Intensity effect, Ratio Fossil Renewal Energy effect, Ratio Capital Labour substitution, and Ratio Household over Labour Force signified the decreasing significance of less household energy subsidy. On the panel ARD-ECM, we identified a negative sign speed-of-adjustment and significant at $1 \%$. It implied that all the ten variable effects were converging in the long run after an experience shocks. The equation parameters were considered stable since the CUSUM gets inside the two critical lines. Additional RESET test of the stability to ascertain whether the estimated model was linear or correctly specified has been performed.

Keywords: LMDI, KAYA Index, ARDL, Households Subsidies Energy

\section{R E S E A R C H H I G H L I G H T S}

Ang (2015) provided a rundown of IDA's advantages and drawbacks, advocating for the logarithmic average divisia index (LMDI) for general use. LMDI was already used by the IEA then widely followed by most researchers in the field of energy. LMDI was used to replace the Laspeyres index in early 1990 and then AMDI. Research on decoupling analysis between economic-GDP growth and $\mathrm{CO} 2$ emissions to provide indicators of determining factor measurement or energy consumption had become popular since the OECD environment minister in 2001 placed it as the OECD's environmental strategy. Then popularity grew in popularity as several studies, such as Kojima and Bacon (2009) also de Freitas and Kaneko (2011), combined decoupling with an index decomposition approach. Some researchers then combined decoupling decomposition analysis with LMDI and econometrics methods such as VECM (Moutinho, Madaleno, \& Silva, 2015; Sadikova, Faisal, \& Resatoglu, 2017; Wu, 2014; Zhao, Zhang, Li, Shao, \& Geng, 2016). 


\section{G R A P I C A L A B S T R A T}

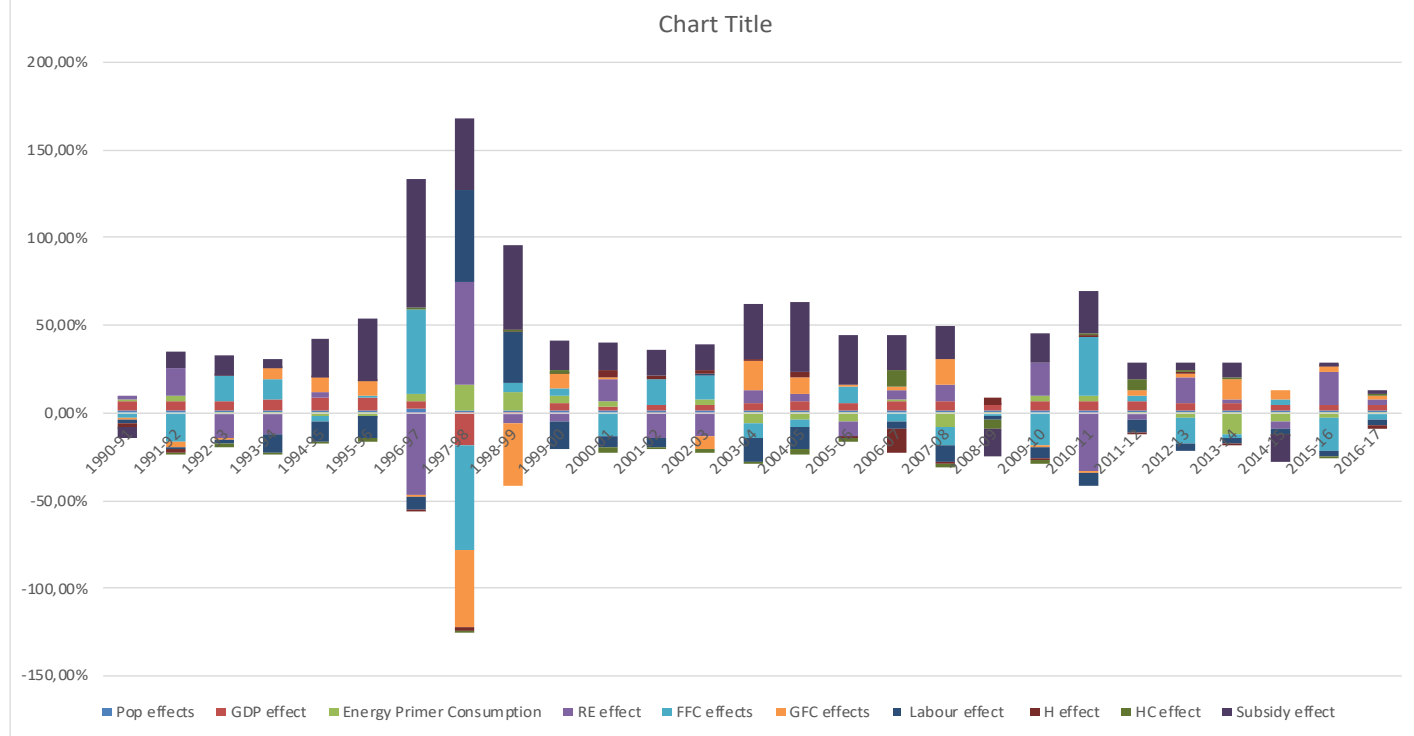

Fig. 1. Energy Subsidy Decomposition

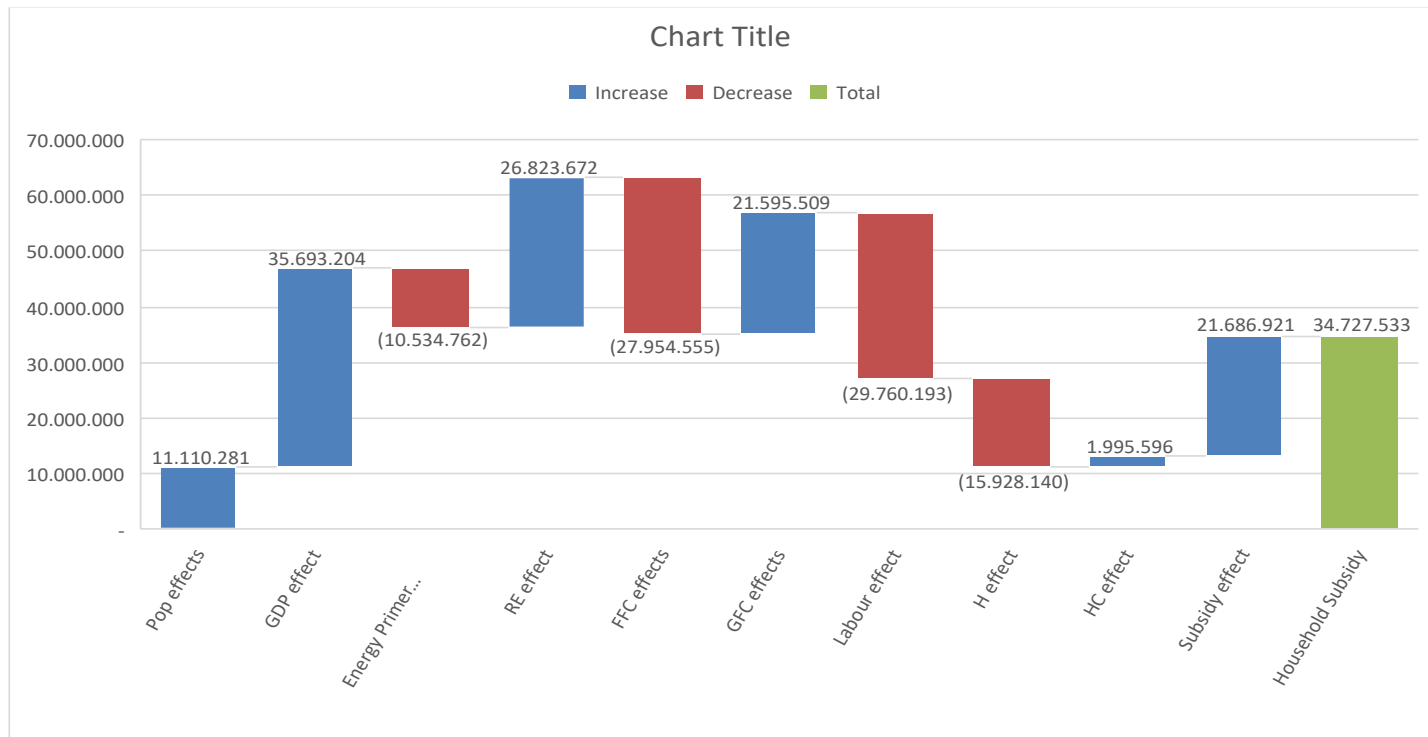

Fig. 2. Energy Subsidy Decompositi

\section{Research Objectives}

The objectives to be achieved in this study were the first investigate the impacts of energy subsidy and how the government explores energy savings targets for 2025 and 2050 in line with Government expectations. Therefore, this study analyzed mainly the relationship between GDP, household energy consumption, and energy subsidies from 1990 to 2017. The Logarithmic Mean Divisia Index (LMDI) and kaya index were used to recognize the decisive technical, economic, and social effects that drive Indonesia's energy subsidy's evolution. 


\section{Methodology}

Researchers used a regression method in data analyst techniques through the decomposition approach using the Logarithmic Mean Divisia Index (LMDI) and KAYA index. ARDL analysis was used to recognize the technical, economic, and social effects that drive the evolution of energy subsidies in Indonesia. The regression analysis was a statistical technique to model and investigated nine independent variables on one response variable (Dependent variable). The regression equation used was as follows:

\section{$Y=\alpha+\beta_{1} P O P+\beta_{2} I P+\beta_{3} E I+\beta_{4} R E+\beta_{5} F R+\beta_{6} I E+\beta_{7} K L+\beta_{8} H S+\beta_{9} S E+e$}

Description:

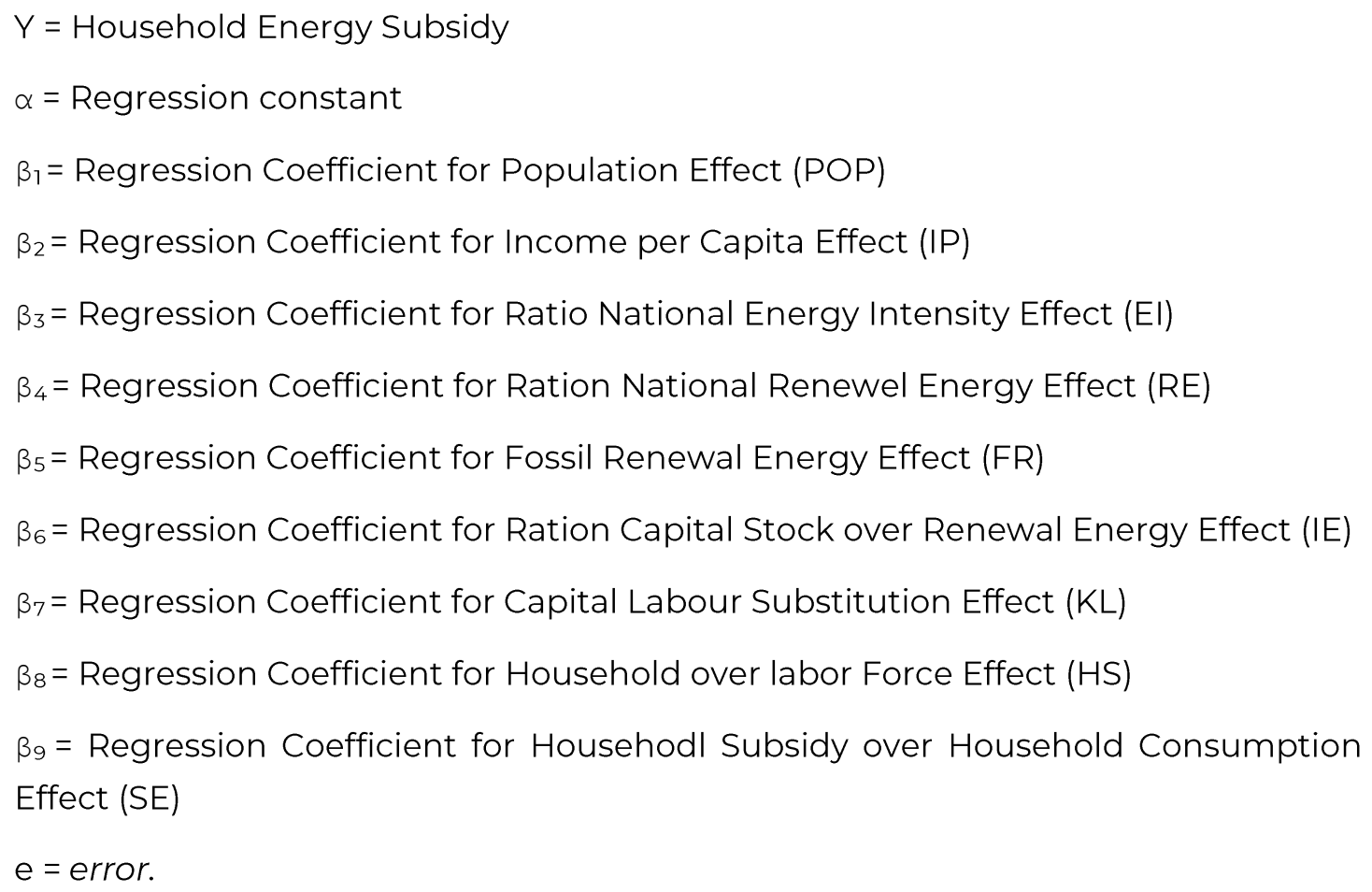

\section{Results}

Based on LMDI results, we found out that the economic aspects were the most significant factors aggravating energy consumption change for the household. Energy efficiency has been the cornerstone in controlling the rising energy used in a household. The negative sign of subsidy energy signifies the decreasing significance of less energy subsidy). The result showed that the models' approximate results show that the ECT coefficient was almost negative, -2.056, with long-term statistical causality. It had been shown that the long-term balance of $\Delta$ HES was valid significant with $5.73 \%$. It meant that the previous period's imbalance shocks reconnected into a long-run equilibrium. In other words, there was a long-term causality between $\Delta$ HES with the other nine variables.

Under ECM, there were no anomalies in the CUSUM square test. We established that the models were stable. The equation parameters were stable for households as the entire total of recursive errors gets within the two critical lines. The equation parameters were stable 
as the entire sum of recursive errors gets within the two critical lines. Based on the CUSUM measure, the overall outcomes were considered stable. Based on the outcome, the null hypothesis of heteroscedasticity should not be discarded since the p-value carried out approaches the significance stage. It was, therefore, presumed that heteroscedasticity does not impact the specified ECM.

\section{Findings}

The long-term result showed that nine variables had a negative-effect energy subsidy ( $\triangle \mathrm{HES}$ ). The empirical result above showed that all variable effects have a significant impact at the 0.01 level and 0.05 for GFC-effect in the long-run causality. Except for Populationeffect had a positive effect with coefficient 1.595 have a significant impact at the 0.05 . It did mean that $1 \%$ change in Population-effect increased 1.595\% in energy subsidy. On the other hand, for all nine variables that had adverse effects, $1 \%$ change in each nine-variables decreased as much as per coefficient stated. The result showed that the models' approximate results showed that the ECT coefficient was almost negative, -2.056, with long-term statistical causality. It has been shown that the long-term balance of $\triangle H E S$ was valid significant with $0.01 \%$. It means that the previous period's imbalance shocks reconnected into a long-run equilibrium. In other words, there was a long-term causality between $\Delta$ HES with the other nine variables.

\section{References}

Ang, B. W. (2015). LMDI decomposition approach: A guide for implementation. Energy Policy, 86, 233-238.

de Freitas, L. C., \& Kaneko, S. (2011). Decomposing the decoupling of CO2 emissions and economic growth in Brazil. Ecological Economics, 70, 1459-1469.

Kojima, M., \& Bacon, R. (2009). Changes in CO 2 Emissions from Energy Use.

Moutinho, V., Madaleno, M., \& Silva, P. M. (2015). Which factors drive CO2 emissions in EU15? Decomposition and innovative accounting. Energy Efficiency, 9(5), 1087-1113.

Sadikova, M., Faisal, F., \& Resatoglu, N. G. (2017). Influence of energy use, foreign direct investment, and population growth on unemployment for the Russian Federation. Procedia Computer Science, 120, 706-711.

Wu, J. (2014). Urban ecology and sustainability: The state-of-the-science and future directions. Landscape and Urban Planning, 125, 209-221. https://doi.org/10.1016/j.landurbplan.2014.01.018

Zhao, X., Zhang, X., Li, N., Shao, S., \& Geng, Y. (2016). Decoupling economic growth from carbon dioxide emissions in China: A sectoral factor decomposition analysis. Journal of Cleaner Production. 